\title{
Documentary heritage: fungal deterioration in Compact Discs
}

\author{
Anna M. Palermo* (10, Antonio Gentile and Giuseppe Pellegrino(i)
}

\begin{abstract}
In recent years, there has been an exponential growth in the use of digital media for data storage and the creation of museums, libraries and digital archives. In particular, Compact Discs Recordable (CD-R) have become one of the most used tools for archiving documents related to cultural heritage. Many authors have investigated only the CD longevity, but very few studies have focused on their biological deterioration. The aim of this work was to examine the CD-R biodeterioration following two ways: (1) search badly preserved CD-R, showing clear degradation spots and verify that it is fungal deterioration; (2) fungal inoculation tests on blank CD-R to verify their bioreceptivity. The analysis of a badly preserved CD-R showed clear degradation spots, highlighting, after cultural and molecular analysis, the presence on the surface of three different fungi: Chaetomium globosum, Trichoderma atroviride e Coniochaeta sp. For the in vitro inoculation tests we used conidia suspensions of Cladosporium cladosporioides and Penicillium chrysogenum, and we observed the growth for 6 months. At the end of experiment, both fungi colonized the CD-R surface with hyphae and mycelia clearly visible, causing also loss of material and fractal structure presence. For the CD-R use as cultural heritage archiving, the correct storage is an essential phase and, in light of the results obtained, it will be necessary not only to consider the environmental factors (temperature, relative humidity) but also the biological deterioration caused by airborne fungi. Therefore, effort needs to be taken to regularly monitor temperature and relative humidity and it is essential to periodically conduct cleaning of optical media.
\end{abstract}

Keywords: Compact Disc, Biodeterioration, Fungi, Cultural heritage archiving

\section{Introduction}

One of the main problems facing the world of cultural goods is that of being able to preserve and transmit all kinds of artifacts. In particular, books, parchments, etc. are kept in libraries and archives or thematic museums. This, however does not ensure them infinite conservation because, being made of organic plant and/or animal materials can be subject to deterioration by physical (light, heat, moisture), chemicals (air pollution) and biological agents (bacteria, fungi, insects) [1].

Furthermore, they can be permanently at risk of theft, robbery, man-made destruction and natural disasters such as hurricanes, earthquakes, floods, etc.

*Correspondence: anna_maria.palermo@unical.it

Department of Biology, Ecology and Earth Sciences - DiBEST, University of Calabria, 87036 Rende, CS, Italy
It is the duty of all who deal with the preservation of cultural heritage, to implement the best possible methods to avoid losses and to maintain a better environment for storage and to prevent all types of damage, allowing the cultural good to to be preserved for as long as possible.

Recently, photographic documents, magnetic and optical media such as Compact Discs Recordable (CD$\mathrm{R})$ have gained the upper hand by steadily stabilizing throughout the world as a means of conservation, thanks also to the progress of technology. Indeed, many new institutions such as museums have been created, digital libraries and archives, which could increase significantly in the future [2].

The reliability of optical memories depends on many factors: their linkage to the quality of the media used and the burning process employed, the environmental conditions, handling and the passage of time [3].

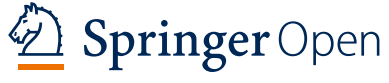

(c) The Author(s) 2021. Open Access This article is licensed under a Creative Commons Attribution 4.0 International License, which permits use, sharing, adaptation, distribution and reproduction in any medium or format, as long as you give appropriate credit to the original author(s) and the source, provide a link to the Creative Commons licence, and indicate if changes were made. The images or other third party material in this article are included in the article's Creative Commons licence, unless indicated otherwise in a credit line to the material. If material is not included in the article's Creative Commons licence and your intended use is not permitted by statutory regulation or exceeds the permitted use, you will need to obtain permission directly from the copyright holder. To view a copy of this licence, visit http://creativecommons.org/licenses/by/4.0/. The Creative Commons Public Domain Dedication waiver (http://creativeco mmons.org/publicdomain/zero/1.0/) applies to the data made available in this article, unless otherwise stated in a credit line to the data. 
Optical media work best within a specific range of temperature and relative humidity conditions. If kept in cooler temperatures and less humid environment and are not subject to sudden environmental fluctuations, they can reach great longevity. Exposure to light and moisture influences the longevity of optical media too, causing a degradation that is different depending on the type of support.

Among the most common causes of digital material deterioration (including $\mathrm{CD}-\mathrm{R}$ ), are high temperature and relative humidity, air pollution (dust carrying bioaerosol and biological agents), poor ventilation conditions of storage its.

The need to investigate the longevity of the information stored on the CD-R is based on ISO 18927-2002 [4], which concerns methods for estimating the life expectancy. The methodology provides a technically and satistically sound procedure for obtaining and evaluating accelerated test data. It is about an accelerated artificial ageing test under extreme conditions of temperature $\left(+80{ }^{\circ} \mathrm{C}\right)$ and relative humidity $(85 \%)$ [5]. Subsequently, many research groups published their results on the evaluation of the estimated longevity value, accelerating ageing to multiple values of temperature and relative humidity to ensure a duration of over 30 years $[6,7]$.

Of the physical and chemical degradation of these devices, four mechanisms are acknowledged: delamination, oxidation, corrosion and dye degradation. The degradation of the dye is also accelerated by exposure to light, in particular sunlight or artificial sources of ultraviolet light [8].

However, both $\mathrm{CD}-\mathrm{R}$ producers and researchers who study the durability of these media in historical and artistic archiving have never considered biological deterioration as a major problem.

In 2001, a unique fungus reported as a Geotrichumtype fungus, was isolated from the surface of a deteriorate $C D$ [9]. The growth of this fungus was accompanied by the presence of fractal-like structures on the alveoli of a CD spiral and the destruction of the aluminium zones. Their in vitro tests showed that this fungus was able to solubilize the aluminium present in the reflective layers of $\mathrm{CD}$ and to degrade the polycarbonate support as well as the phthalocyanine dye layer [10].

In recent years, the use of digital media for data storage and CD-R has also spread to archiving documents related to cultural heritage. Their study to date, has covered only much the chemical-physical deterioration mechanism and the duration of their life, through a series of tests as accelerated aging test to find a right way for their maintenance $[3,6,7]$.

At present, there are no studies on the biological deterioration of $\mathrm{CD}-\mathrm{R}$; the only exception is the work of
Romero et al. [10] who conducted a molecularly identification of a Geotrichum-type fungus on such types of media.

The aim of this work was to examine the CD-R biodeterioration following two ways:

(1) search badly preserved CD-R, showing clear degradation spots and verify that it is fungal deterioration;

(2) fungal inoculation tests on blank CD-R to verify their bioreceptivity.

The methodologies used to achieve these purposes considered microscopy (optical and SEM), culture techniques and molecular investigations using rDNA sequencing.

\section{Materials and methods CD composition}

A CD is a circular disc of $12 \mathrm{~cm}$ in diameter and of 1.2 mm thick. It is constructed of three or four main functional layers. It is composed of a polycarbonate plastic substrate, is exposed to a stream of vaporized aluminum, which forms the reflective layer, and is then coated with a protective acrylic layer. A label can be added onto the acrylic if desired.

A CD is shiny on the bottom side and dully on the upper side that usually has a label.

The shiny side is the important part; this reflects the laser that is used to read the device. Data is encoded by the transitions between pits and lands of the polycarbonate $[3,8]$.

\section{Analysis of a badly preserved CD showing clear degradation spots}

A CD (Verbatim) with signs of clearly visible deterioration spots was found in a home library (Fig. 1). After stereomicroscope observation, the $\mathrm{CD}$ was dissected into three parts at the signs of deterioration and the fragments were placed in Petri capsules containing MEA (Malt Extract Agar) wich is a specific culture medium for fungi.

The capsules were then placed in a thermostatic cell at $25{ }^{\circ} \mathrm{C}$, and observed every day. After about 10 days, fungal growths were detected in all three CD portions and fungi sample collected were used for molecular analyses in order to identify them.

For DNA extraction we used CTAB (cethyltrimethylammonium bromide) micropreparation method [11] using before, both the freezing and thawing method.

After extraction, the DNA was amplified with specific primers for fungi: ITS1F $5^{\prime}$ CTTGGTCATGAGAAGTAA 3'/ITS45'CAGGAGACTTGTACACGGTCCAG3' [12]. 


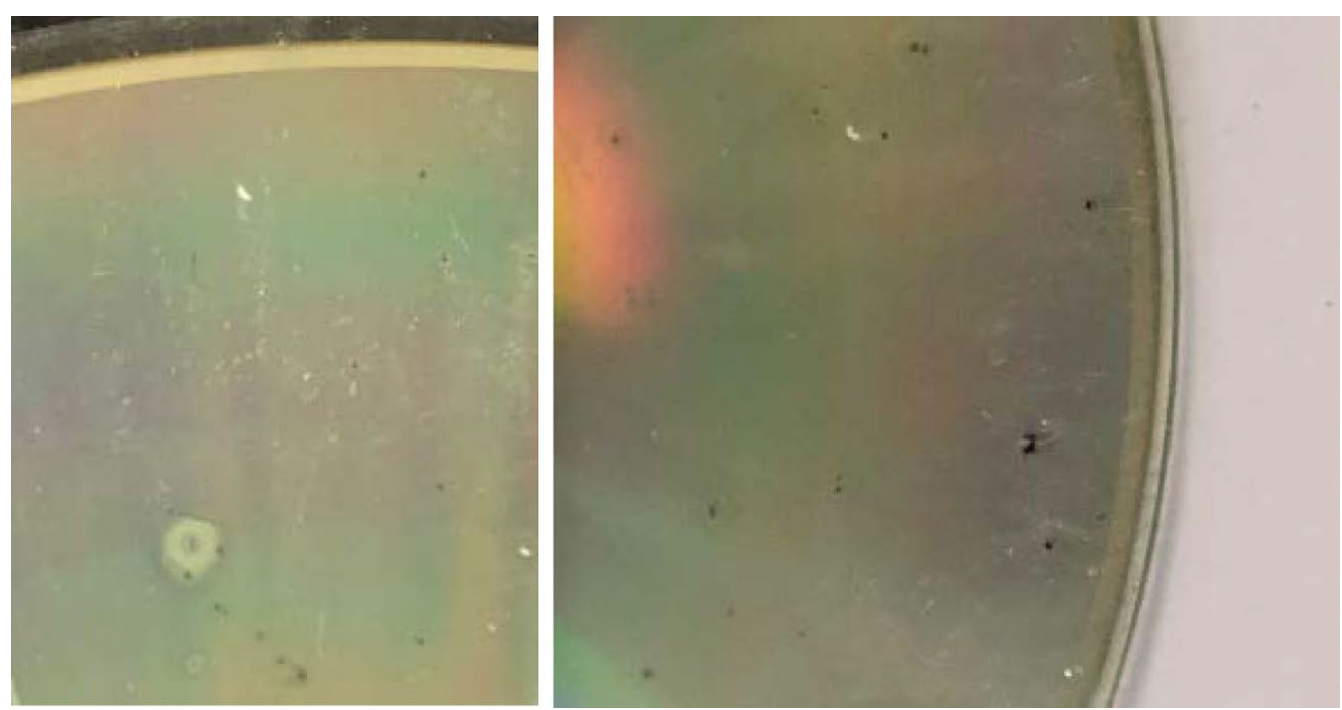

Fig. 1 Detail of the damaged CD. Visible deterioration spots on upper side of the CD

The PCR reaction was performed on a PTC-100 Thermal Cycler (MJ Research Inc. Watertown, MA, USA) using PCR Master Mix (Bioline Inc. Boston, MA, USA). The reaction was carried out in a $25 \mu \mathrm{L}$ volume containing $0.5 \mathrm{pmoL}$ of each primer, $1 \mu \mathrm{L}$ of $\mathrm{MgCl}_{2}, 10 \mu \mathrm{L}$ of buffer Master mix and $1 \mu \mathrm{L}$ Dna as template. The thermocycling program was as follows: 3 min denaturation at $94^{\circ} \mathrm{C}$, followed by 35 cycles of $30 \mathrm{~s}$ denaturation at $94{ }^{\circ} \mathrm{C}, 1 \mathrm{~min}$ annealing at $55^{\circ} \mathrm{C}$, and $45 \mathrm{~s}$ extension at $72{ }^{\circ} \mathrm{C} .10 \mathrm{~min}$ at $72{ }^{\circ} \mathrm{C}$ were used as a final extension step.

The samples, after purification, were sequenced at BMR Genomics in Padova (Italy) following the preparation protocol suggested by the same company.

Sequences were edited and assembled using BioEdit software [13], and sequence identity was determined using the BLASTn algorithm available through the National Center for Biotechnology Information (NCBI, http://www.ncbi.nlm.nih.gov/) against the NCBI nucleotide collection.

\section{Fungal inoculation tests on blank CD-R}

Fungi used for in vitro tests were selected based on literature research in archives and libraries and in the field of polycarbonate deterioration [14-17]. Many fungi have been already present in the stock culture in the Plant Biosystematic Laboratory of the University of Calabria and of these, two have been chosen: Cladosporium cladosporioides and Penicillium chrysogenum.

The two fungi were growth on Malt Extract Agar at $25^{\circ} \mathrm{C}$ for 7 days. The conidia suspensions were obtained by gently scraping the surface of the agar plates with a plastic swab and stored at $0.05 \% \mathrm{NaCl}$ and the conidia concentration was valuated by a Thoma counting chamber $\left(22.96 \times 10^{6}\right.$ conidia/mL for Cladosporium cladosporioides and $14.96 \times 10^{6}$ conidia/mL for Penicillium chrysogenum).

For laboratory tests the $\mathrm{CD}$ was carefully dissected using a Dremel rotary tool and then autoclaved. The incubation was performed at room temperature in a Petri dish divided in two parts by a separating septum, so as to have the chosen sample on one side and distilled water on the other, to keep the high humidity level constant (Fig. 2).

Both the upper and bottom sides of the CD-R were used for inoculation three drops of $5 \mu \mathrm{L}$ and $7 \mu \mathrm{L}$ of conidic suspension of Penicillium chrysogenum and Cladosporium cladosporioides.

The samples were monitored every day for 6 months with a stereomicroscope and an optical microscope and were collected the acquired images.

SEM analysis was performed on the CD upper and bottom side. The scanning electron microscope used for SEM analysis is a Field Emission Gun (FEG) Cold FEI Quanta 200 F/Philips with an EDX microanalysis system with a crystal detector $\mathrm{Si} / \mathrm{Li}$, EDAX GENESIS 4000. Samples were fixed to an aluminium stub and coated with a thin film of gold in a Sputter Coater (Q150T ES - QUORUM TECHNOLOGIES).

\section{Results}

Analysis of a badly preserved CD showing clear degradation spots

The three fragments of $C D$ placed for about 2 weeks in Petri capsules showed several colonies that were collected and subjected to further molecular analysis. 

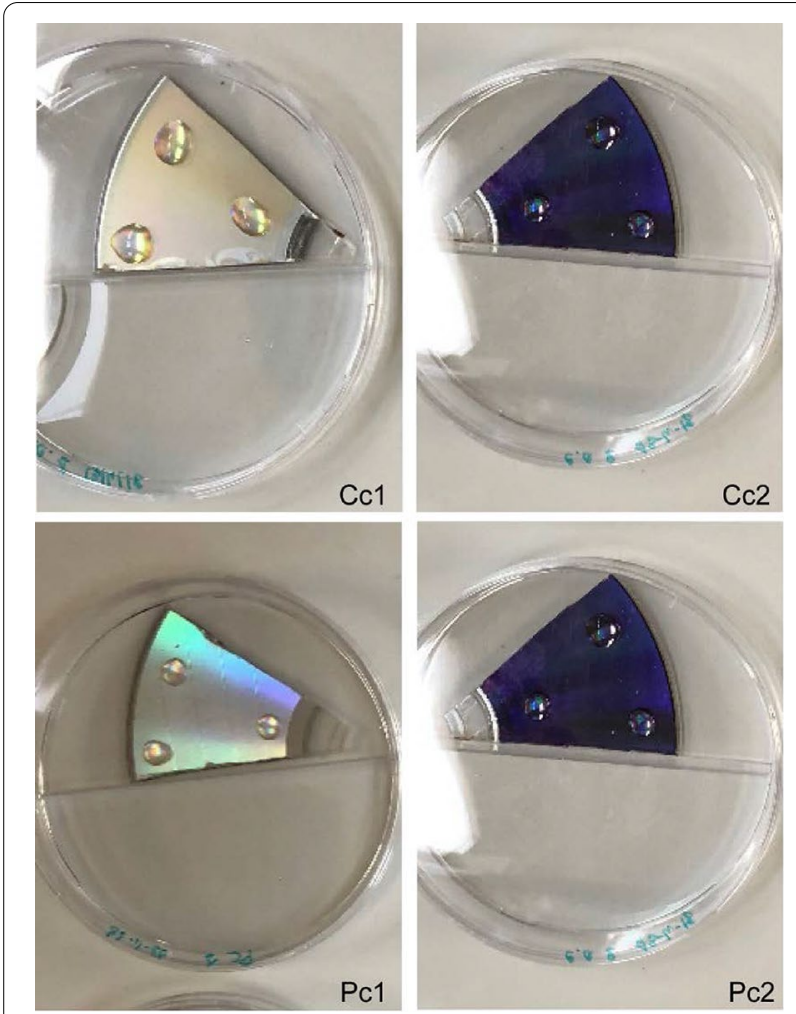

Fig. 2 Inoculum points of the two fungi on both sides of the CD. CC (Cladosporium cladosporioides), PC (Penicillium chrysogenum), 1 (upper side), 2 (bottom side)

On fragments CD1 and CD2 grew only one different fungal colony, which surrounded the whole piece and also spread on the ground, while two colonies grew on third fragment, one of which to a greater extent around the entire CD fragment (CD3a) and the other much smaller towards the upper edge (CD3b) (Fig. 3).

The PCR analysis produced four fragments of the ribosomal DNA, whose sizes varied between 571 and 603 bp. All fragments were sequenced, deposited in GenBank and subjected to BLAST analysis.

The ribosomal DNA sequences of samples CD1 and CD3b (accession number MW073465) showed 100\% identity with several sequences deposited in GenBank of Chaetomium globosum; the sequence of sample CD2 (accession number MW073467) showed 100\% identity with those of Trichoderma atroviride; the sequence of sample CD3a (accession number MW073470) showed 99-100\% identity with the ITS region of several species of genus Coniochaeta such as C. ligniaria and $C$. hoffmannii.

\section{Fungal inoculation tests on blank CD-R}

On the upper side, after about ten days both fungi colonized the inoculation point with hyphae development

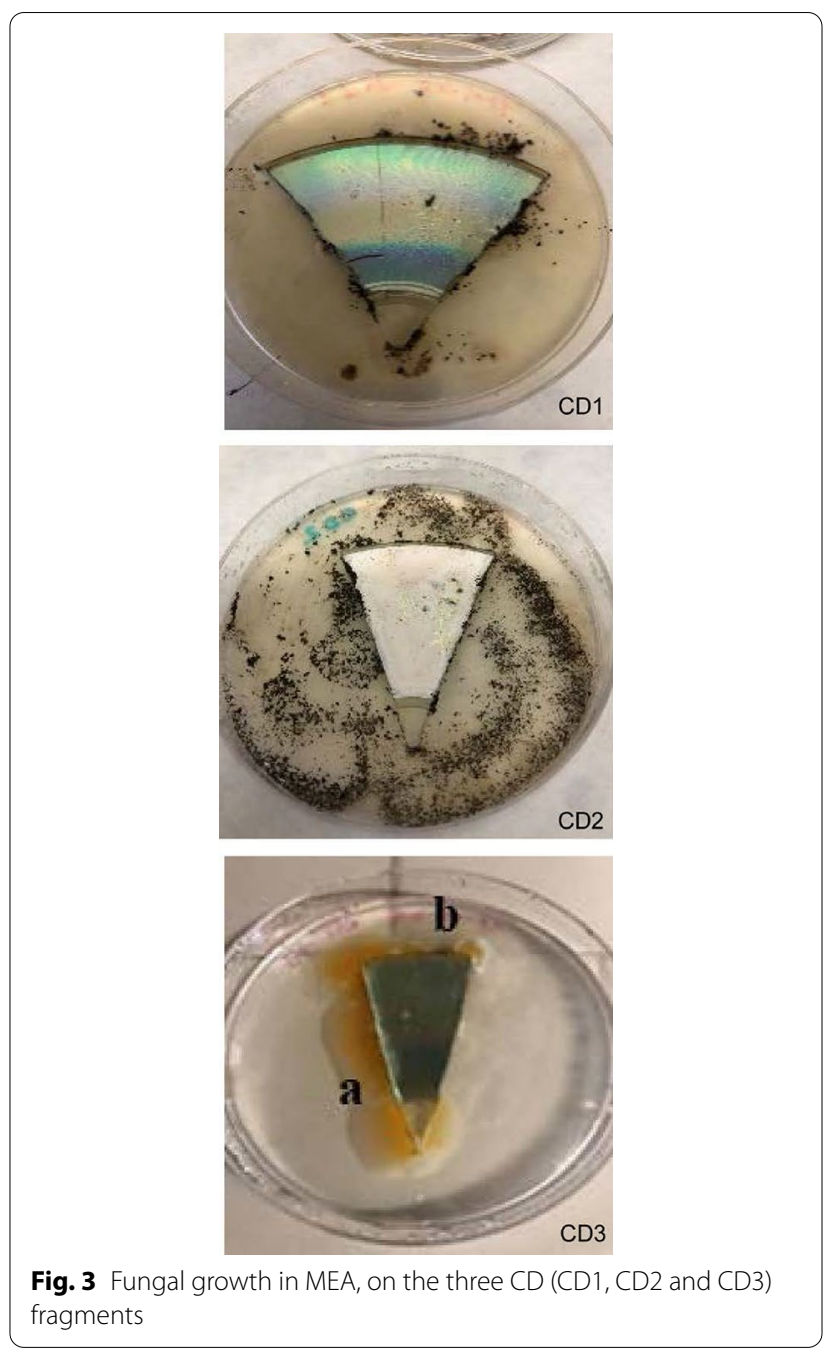

(Fig. 4a). After 2 months the fungal mycelium was in expansion (Fig. 4b) and after 3 months the development of the conidiophores with their sporulation was visible (Fig. 4c and d). After 6 months of incubation, the fungal mycelia with hyphae covered the whole surface (Fig. 4e), and the hyphae and conidiophores were visible also on the edges (Fig. 4f). Furthermore, the loss of material on the surface was clearly visible (Fig. $4 \mathrm{~g}, \mathrm{~h}$ ), and subsequently the surface became transparent in some areas meaning that the layers of the CD have been almost completely degraded (Fig. 4i). Moreover, optical microscopy and SEM analyses showed the presence of fractal structures (Fig. 4j-l).

On the bottom side, colonization of the two fungi was much rapid. Only after 1 day after inoculation, hyphae grew and quickly covered the entire surface of the CD (Fig. 5a). Both mycelia and conidiophores (Fig. 5b and c) were evident towards the end of the first month at the inoculation points and continued to grow over the entire 

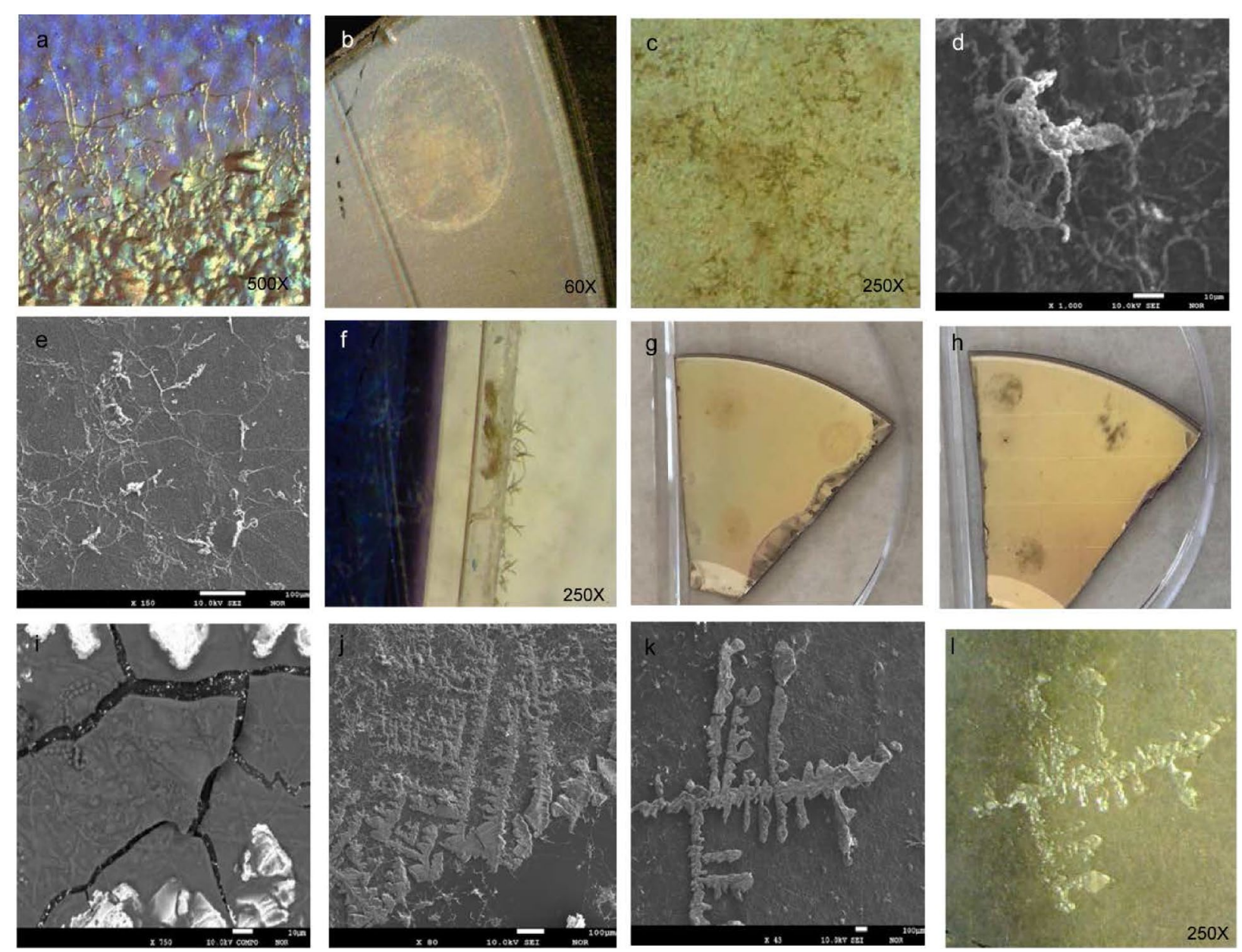

Fig. 4 CD upper side. a Hyphae; $\mathbf{b}$ mycelium; $\mathbf{c}-\mathbf{e}$ conidiophores and hyphae on surface; $\mathbf{f}$ hyphae and conidiophores on the edges; $\mathbf{g}$-i loss of material on the surface; $\mathbf{j}-\mathbf{I}$ fractal structures

surface (Fig. 5d and e). The transparent areas with loss of material were evident from the first month.

After 6 months, the $C D$ fragments were completely deteriorated on both sides, in fact the presence of fungi, especially Penicillium chrysogenum, can be perfectly observed on the two sides of the CD (Fig. 5f, g). The fractal structures appeared transparent after 2 months of incubation which was already evident under the stereomicroscope and even more evident in the SEM images (Fig. 5h-l).

\section{Discussion}

The analysis of a badly preserved CD showed clear degradation spots, highlighting the presence on the surface of three distinct fungi: Chaetomium globosum, Trichoderma atroviride e Coniochaeta sp.

For the in vitro inoculation tests with Cladosporium cladosporioides and Penicillium chrysogenum, both fungi were clearly visible on both $C D$ sides.
The fungal attack of Cladosporium cladosporioides was rapid and the mycelium grew immediately. At the end of the experiment, the mycelia were growing up on both sides, causing also loss of material and fractal structure presence.

Penicillium chrysogenum was faster in growth on both sides with significant presence of mycelium and conidiophore structures. The entire bottom side was covered with the hyphae, and it showed many fractal structures. Penicillium chrysogenum contributed significantly to the physical destruction of the CD fragments, so much so that in some places the $\mathrm{CD}$ has become almost transparent.

In comparation to Penicillium chrysogenum, Cladosporium cladosporioides, a fungus known for the biodeterioration of photographic materials [18], showed a greater tendency to degrade the composition material of CD. 

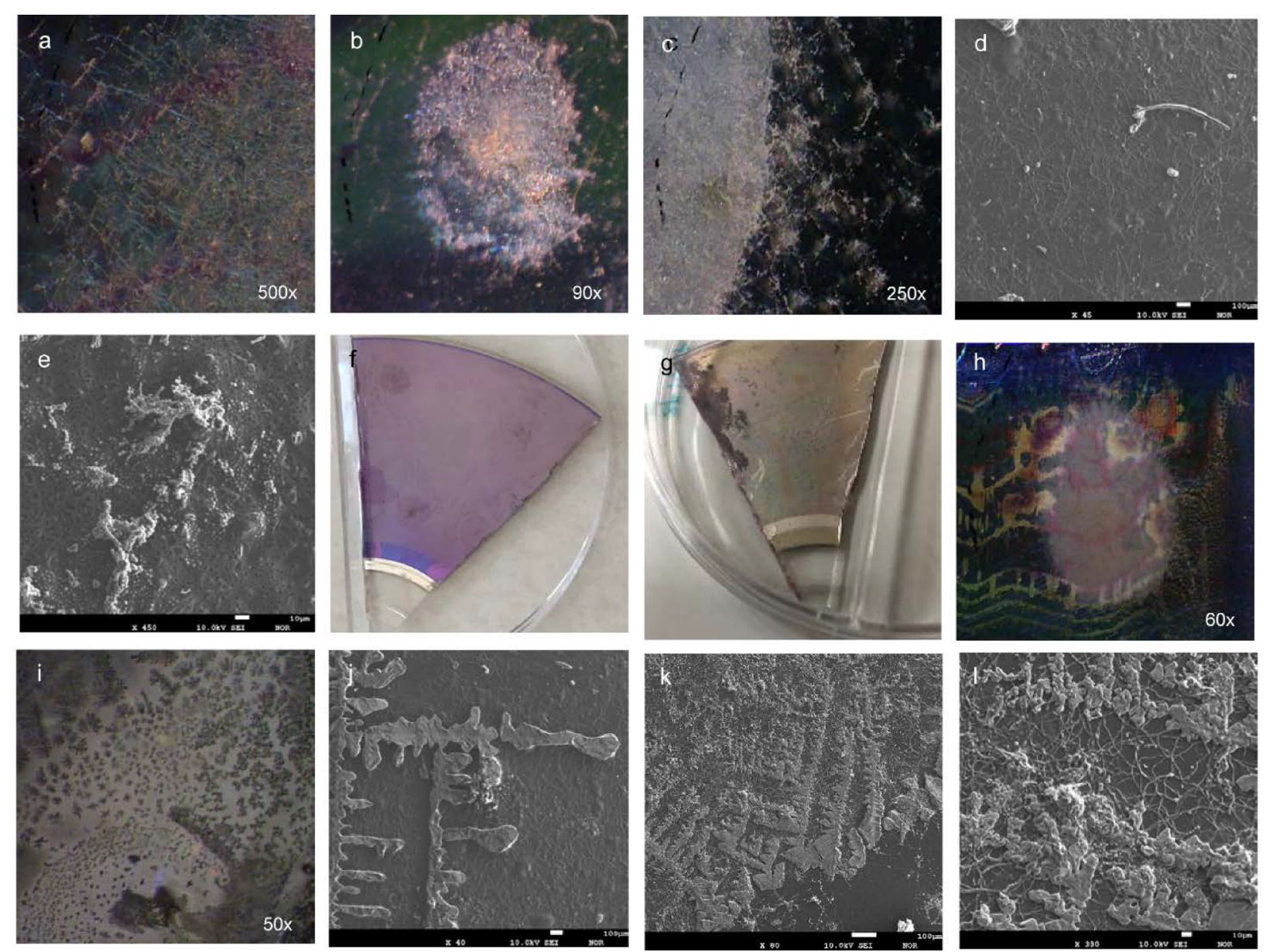

Fig. 5 CD bottom side. a Hyphae; $\mathbf{b}$, c-e mycelia and conidiophores; $\mathbf{f}$, $\mathbf{g}$ surface deteriorated; $\mathbf{h}-\mathbf{I}$ fractal structures

The CD- $\mathrm{R}$ is a form of digital media that can be encoded with digital data and is mainly composed of polycarbonate, usually poly (bisphenol A carbonate), a thermoplastic polymer of carbonic acid, consequently, biodeterioration of the $\mathrm{CD}$ is biodeterioration of the polycarbonate and in general plastic materials, polymers mainly made of carbon.

Plastics are chemically synthesized polymers that are difficult to degrade. Normally, plastic degradation is very slow process and it is influenced by various environmental factors (air humidity, temperature, $\mathrm{pH}$, solar energy, polymer properties) [19]. Microorganisms such as bacteria and fungi are involved in the degradation of plastic materials [20].

Generally, biodeterioration of organic and inorganic materials including, also, polymers was defined by Hueck [21] as "any undesirable change in the properties of a material caused by the vital activities of microand/or organisms".
This definition is associated with that of biodegradation, the process in which organic substances are broken down by living organisms [14]. This process involves enzymatic and non-enzymatic hydrolysis of microorganisms, especially bacteria, and fungi [15, 22]. At least two categories of enzymes are actively involved in biological degradation of polymers: extracellular and intracellular depolymerases [20, 23]. During degradation, exoenzymes from microorganisms break down complex polymers to smaller molecules, for example, oligomers, dimers, and monomers, that are smaller enough (water soluble) to pass the semi-permeable outer bacterial membranes and then to be utilized as carbon and energy sources [15, 24]. The process is called depolymerization and the complete polymer decomposition produces organic acids, $\mathrm{CO}_{2}$, $\mathrm{CH}_{4}$ and $\mathrm{H}_{2} \mathrm{O}[14,24]$.

Currently, the studies carried out on CD-R and their deterioration have considered the mechanisms of chemical degradation, such as oxidation or corrosion 
and, although the mechanisms are well known, they can be accelerated by high temperature and relative humidity. A greater number of studies have concerned their life expectancy by carrying out longevity tests since natural deterioration can derive from storage environments and from temperature and humidity parameters [5-7] and large variations have been demonstrated for less than fifteen years $\left(25^{\circ} \mathrm{C}\right.$, humidity relative $\left.50 \%\right)$ at 217 years $\left(25^{\circ} \mathrm{C}, 40 \%\right.$ relative humidity) [25].

$\mathrm{CD}$ producers, however, have not troubled about their biological deterioration and just one research [9] ascertained the presence of Geotrichum-type fungi, probably Geotrichum candidum able to growing on a $\mathrm{CD}$ in tropical environmental conditions (around $30{ }^{\circ} \mathrm{C}$ and RH 90\%).

They observed on the CD surface paths, which formed fractal structures and destruction of the pits and halls in the aluminum on the disc which, by light and scanning electron microscopy, revealed dendrite microstructures of aluminum-polycarbonate mixtures and the complete loss of the original information pits [9].

On CD inoculated in vitro with Cladosporium cladosporioides e Penicillium chrysogenum, deterioration of these material resulted in reduced transparency of the sample, staining and presence of fungal spores and hyphal fragments. After a long-term exposure the $\mathrm{CD}-\mathrm{R}$ were covered by fungal hyphae, over the surface. We observed, as in the work of Garcia-Guinea [9] the presence of paths, which formed fractal structures, and destruction of the pits and halls in the aluminum on the disc.

On badly preserved CD the presence of Chaetomium globosum, Trichoderma atroviride and Coniochaeta sp. can be explained by the fact that all are involved in the degradation of lignin and cellulose, using the carbon of polycarbonate as a source of nourishment and energy. In fact, it is known that Chaetomium globosum produces cellulose enzymes and has the ability to degrade cellulosic materials and the production of these enzymes was found to depend on the growth substrate [26]. In addition, Trichoderma atroviride is a ubiquitous fungus and colonizes cellulosic materials, and shows ability in the efficient utilization of the substrate [27]. Lastly, several fungi in the genus Coniochaeta have great capacity to deconstruct lignocellulose by secreating lignocellulose-degrading enzymes into the media utilising different substrates as source of carbon and energy [28].

The presence of fungi both used in vitro and found on deteriorated $C D$ is confirmed by the many works carried out both in the field of cultural heritage $[1,29,30]$ and in the deterioration of plastic materials $[15,31,32]$.

\section{Conclusions}

Heritage institutions traditionally have the responsibility of preserving the intellectual and cultural resources. Optical memories, in recent years, have been widely used for the preservation of digital documents over time, so much so that they were also employed in archivation (to the point that guidelines had to be formulated by the UNESCO/PERSIST Content Task Force). The aim of the Guidelines is to provide a starting point for libraries, archives, museums and other heritage institutions when drafting their own policies on the selection of digital heritage for long-term sustainable digital preservation [33].

Reliability of optical memories depends on the storage conditions. In this study the molecular biology techniques are important diagnostic tools, providing more knowledge on fungal species which attack $C D$ and on their time of material degradation.

For correct storage of CD-R, it is necessary to understand if the presence of fungi can become a problem together with the action of environmental factors.

Therefore, not only the temperature and humidity conditions are important, but periodic cleaning of optical media is essential as well.

The long-term preservation of digital heritage is perhaps the most daunting challenge facing heritage institutions today. Developing and implementing selection criteria and collecting policies is the first step to ensuring that this vital heritage material is preserved for the benefit of current and future generations.

\section{Acknowledgements \\ We are very grateful to Dr. M. Davoli of the Center for Microscopy and Microa- nalysis for his assistance in SEM images.}

\section{Authors' contributions}

AMP conceived and designed the research. AMP, AG, GP performed the research and analyzed the data. AMP and GP wrote the manuscript. All authors read and approved the final manuscript.

\section{Funding}

Not applicable.

Availability of data and materials

Data and materials are available on request.

\section{Declarations}

Ethics approval consent to participate

Not applicable.

Consent for publication

The authors give their consent for publication.

Competing interests

The authors declare that no competing interests exist.

Received: 29 June 2021 Accepted: 7 October 2021

Published online: 19 October 2021 


\section{References}

1. Maggi O, Persiani AM, Gallo F, Valenti P, Pasquariello G, Sclocchi MC, Scorrano M. Airborne fungal spores in dust present in archives: proposal for a detection method, new for archival materials. Aerobiologia. 2000;16:42934. https://doi.org/10.1023/A:1026522826477.

2. Abduraheem K, Zarrin A. Digital documentation of manuscripts: prospects and constrains.http://network.icom.museum/fileadmin/user_ upload/minisites/cidoc/ConferencePapers/2015/2_Digital_Preservation. pdf. (2015). Accessed 25 Mar 2020.

3. Allegrezza $\mathrm{S}$. The reliability of optical memories in the long-term preservation of digital documents. JLISit. 2015;6(2):101-25. doi:https://doi.org/ 10.4403/jlis.it-11146.

4. ISO. (2002). Imaging materials - Recordable compact disc systemsMethod for estimating the life expectancy based on the effects of temperature and relative humidity (ISO 18927:2002).

5. Dobrusina SA, Ganicheva SI, Tikhonova IG, Velikova D, Zavalishin PE. Influence of external factors on the longevity of information recorded on dvd $\pm r$ discs. Sci Tech Inf Proc. 2007;34(5):258-63. https://doi.org/10.3103/ S0147688207050036.

6. Lee K-Y, Lim D-S, Kim K-H, Cho W-I, Kim Y-J. Evaluation of data stability and analysis of degradation factors of digital versatile disk recordable $(d v d+r)$ for archival application. Jpn J Appl Phys. 2012. https://doi.org/10.1143/ JJAP.51.08JC01.

7. Iraci J. Longevity of optical disc media: accelerated ageing predictions and natural ageing data. Restaurator. 2017;38(3):273-98. https://doi.org/ 10.1515/res-2016-0032.

8. Lunt BM, Linford MR. Family history archives: research on new media. Proceedings of the Family History Technology Workshop. 2010.Salt Lake City, UT, USA

9. Garcia-Guinea J, Càrdenes V, Martìnez AT, Martìnez MJ. Fungal bioturbation paths in a compact disk. Naturwissenscaften. 2001:88:351-4. https:// doi.org/10.1007/s001140100249.

10. Romero E, Speranza M, Garcia-Guinea J, Martìnez AT, Martìnez MJ. An anamorph of the white-rot fungus Bjerkandera adusta capable of colonizing and degrading compact disc components. FEMS. Microbiol Lett. 2007:275:122-9. https://doi.org/10.1111/j.1574-6968.2007.00876.x.

11. Doyle JJ, Doyle JL. A rapid DNA isolation procedure for small quantities of fresh leaf tissue. Phytochemical Bulletin. 1987;19:11-5.

12. White TJ, Bruns T, Lee S, Taylor JW. Amplification and direct sequencing of fungal ribosomal RNA genes for phylogenetics. In: Innis MA, Gelfand $\mathrm{DH}$, Sninsky JJ, White TJ, editors. PCR protocols: a guide to methods and applications. New York: Academic Press Inc; 1990. pp. 315-22. https://doi. org/10.1016/B978-0-12-372180-8.50042-1.

13. Hall TA. BioEdit: a user-friendly biological sequence alignment editor and analysis program for Windows 95/98/NT. Nucl Acid S. 1999;41:95-8.

14. Devi RS, Kannan VR, Natarajan K, Nivas D, Kannan K, Chandru S, Arokiaswamy RA. The role of microbes in plastic degradation. In: Ram C, editor. Environmental waste management. Boca Raton: CRC; 2016. pp. 341-70. doi:https://doi.org/10.1201/b19243-13.

15. Bonhomme S, Cuer A, Delort AM, Lemaire J, Sancelme M, Scott C. Environmental biodegradation of polythene. Polym Degrad Stabil. 2003;81:441-52. doi:https://doi.org/10.1016/S0141-3910(03)00129-0.

16. Gu JD. Microbiological deterioration and degradation of synthetic polymeric materials: recent research advances. Int Biodeter Biodegr. 2003:52:69-91. https://doi.org/10.1016/S0964-8305(02)00177-4.

17. Mesquita N, Portugal A, Videira S, Rodríguez-Echeverría S, Bandeira AML, Santos MJA, Freitas H. Fungal diversity in ancient documents. A case study on the archive of the University of Coimbra. Int Biodeter Biodegr. 2009;63(5):626-9.

18. Kosel J, Polonca R. Overview of fungal isolates on heritage collections of photographic materials and their biological potency. J Cult Herit. 2021;48:277-91. https://doi.org/10.1016/j.culher.2021.01.004.

19. Shah AA, Hasan F, Hameed A, Ahmed S. Biological degradation of plastics: a comprehensive review. Biotechnol Adv. 2008;26(3):246-65. https://doi. org/10.1016/j.biotechadv.2007.12.005.

20. Gu JD, Ford TE, Mitton DB, Mitchell R. Microbial degradation and deterioration of polymeric materials. In: Revie W, editor. The Uhlig Corrosion Handbook. New York: Wiley; 2000. pp. 439-60.

21. Hueck HJ. The biodeterioration of materials - an appraisal. In: Walters AH, Elphick JS, editors. Biodeterioration of materials. London: Elsevier; 1968. pp. 6-12.

22. Fesseha $H$, Abebe F. Degradation of plastic materials using microorganisms: a review. Open Public Health J. 2019;4(2):57-63. doi:https://doi.org/ 10.17140/PHOJ-4-136.

23. Hari S. Review on effect of fungi on plastic degradation. JRAR. 2019;6(1):261-5.

24. Hamilton JD, Reinert KH, Hogan JV, Lord WV. Polymers as solid waste in municipal landfills. J Air Waste Manage. 1995;543:247-51. https://doi.org/ 10.1080/10473289.1995.10467364.

25. Haus G, Polizzi C, Visconti A. Preserving cultural heritage: a new approach to increase the life expectancy of optical discs. J Cult Herit. 2018;29:67-74 https://doi.org/10.1016/j.culher.2017.08.004

26. Longoni P, Rodolfi M, Pantaleoni L, Doria E, Concia L, Picco AM, Cella R. Functional analysis of the degradation of cellulosic substrates by a Chaetomium globosum endophytic isolate. Appl Environ Microb. 2012;78(10):3693-705. https://doi.org/10.1128/AEM.00124-12.

27. Schuster A, Schmoll M. Biology and biotechnology of Trichoderma. Appl Microbiol Biot. 2010;87:787-99. https://doi.org/10.1007/ s00253-010-2632-1.

28. Lopez MJ, Vargas-García MC, Suárez-Estrella F, Nichols NN, Dien BS, Moreno J. Lignocellulose-degrading enzymes produced by the ascomycete Coniochaeta ligniaria and related species: application for a lignocelJulosic substrate treatment. Enzyme Microb Tech. 2007;40(4):794-800. https://doi.org/10.1016/j.enzmictec.2006.06.012.

29. Coronado-Ruiz C, Avendaño R, Escudero-Leyva E, Conejo- Barboza G, Chaverri P, Chavarría M. Two new cellulolytic fungal species isolated from a 19th-century art collection. Sci Rep-UK. 2018;8:7492. https://doi.org/10. 1038/s41598-018-24934-7.

30. Rojas TI, Aira MJ, Batista A, Cruz IL, González S. Fungal biodeterioration in historic buildings of Havana (Cuba). Grana. 2012;51(1):44-51. https://doi. org/10.1080/00173134.2011.643920.

31. Lugauskas $A$, Levinskaitè L, Pečiulytè D. Micromycetes as deterioration agents of polymeric materials. Int Biodeter Biodegr. 2003;52:233-42. https://doi.org/10.1016/S0964-8305(03)00110-0.

32. Raziyafathima M, Praseetha PK, Rimal IRS. Microbial degradation of plastic waste: a review. JPCBS. 2016:4(2):231-42.

33. UNESCO. 2016 The UNESCO/PERSIST Guidelines for the selection of digital heritage for long-term preservation.

\section{Publisher's Note}

Springer Nature remains neutral with regard to jurisdictional claims in published maps and institutional affiliations. 